\title{
The tooth factor effect on the harmonics of large electrical machines
}

\author{
Ayman Y. Al-Rawashdeh ${ }^{1}$, Ali Dalabeeh ${ }^{2}$, Abdallah Al-Zeyod ${ }^{3}$, Ashraf Samarah $^{4}$, \\ Ghazi Qaryouti ${ }^{5}$, Omar Albarbarawi ${ }^{6}$ \\ 1,2,3,5,6 Department of Electrical Engineering, Faculty of Engineering Technology, \\ Al-Balqa Applied University, Amman, Jordan \\ ${ }^{4}$ Department of Electrical Engineering, Faculty of Engineering, Al-Balqa Applied University, Al-Salt, Jordan
}

\section{Article Info}

Article history:

Received Mar 9, 2019

Revised Sep 26, 2019

Accepted Mar 23, 2020

\section{Keywords:}

Asynchronous

Harmonics

Magnetic core

Smooth surface

Teeth coefficient

\begin{abstract}
In the current study, the general mathematical model for the calculation and analysis of asynchronous systems and transient cases in asynchronous synchronous large electrical machines was developed. The theory of magnetic fields in the teeth's circuits with a smooth surface of the rotor was used and at the same time, high harmonics of magnetic fields and its effect on the transient cases was also calculated. Performance curves were investigated using Matlab codes and evaluated under different values of $C_{v}$ factor. The results confirmed the possibility of improving the noise harmonics on the sinusoidal wave form, which is reflected on the machines starting.
\end{abstract}

This is an open access article under the CC BY-SA license.

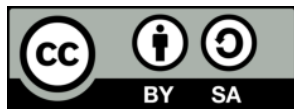

\section{Corresponding Author:}

Ayman Y. Al-Rawashdeh,

Department of Electrical Engineering, Faculty of Engineering Technology

Al-Balqa Applied University,

11134 Marka, Amman, Jordan.

Email: dr.ayman.rawashdeh@bau.edu.jo

\section{INTRODUCTION}

To obtain the magnetic field on a simplified smooth surface of the motor's air gap, analytical methods or mathematical methods can be used. Implementing mathematical methods depends on infinite difference method $[1,2]$. This method is a numerical method for solving differential equations that describe transient cases in machines [3, 4]. At the same time, high harmonics of magnetic fields and its effect on the transient cases is calculated, by maintaining some harmonics suitable for the use of analytical methods and to provide specific information about the harmonics fields [5, 6]. The Conversion function can be obtained by integrating the systems formulae [7, 8]. The harmonics of the Magnetic Flux Density (MFD) in the air gap of an electrical machine depends on the special distribution of the magneto motive force and on the teeth of the magnetic core $[9,10]$. The harmonics of the MFD is usually determined on the surface of a smooth magnetic core. In order to study this problem and calculate harmonic fields for one-side with a number of assumptions (permitting), it is necessary to understand the tooth coefficient $\left(C_{v}\right)$ by using mathematical model for calculating and analysis of the tooth coefficient $\left(C_{v}\right)$ [11]. The concept of the tooth coefficient for arbitrary ( $v-u)$ harmonics of the MFD [12], which is the ratio between the amplitude value of the MFD $\left(B_{v m}\right)$ of a slots and the teeth in the surface of the core in one-sided of the gap to the amplitude value of the MFD $\left(B_{0 v m}\right)$ of the same harmonics for a smooth surface in the other side of the gap [13]. 


\section{RESEARCH METHOD}

\subsection{Calculation of the teeth factor for the $\boldsymbol{v}^{\text {th }}$ harmonics}

To obtain the magnetic field on a smooth surface of the motor's air gap according to special boundary conditions, shown in Figure 1 analytical or mathematical methods can be used [14]. The use of mathematical methods depend on the infinite difference methods. These methods are numerical methods employed for quickly solving differential equations by approximating them with difference equations, in which infinite differences approximate the derivatives. At the same time, it is necessary to calculate the harmonics of magnetic fields and to maintain some harmonics to enable use of analytical methods and to provide specific information about the harmonics fields $[15,16]$.

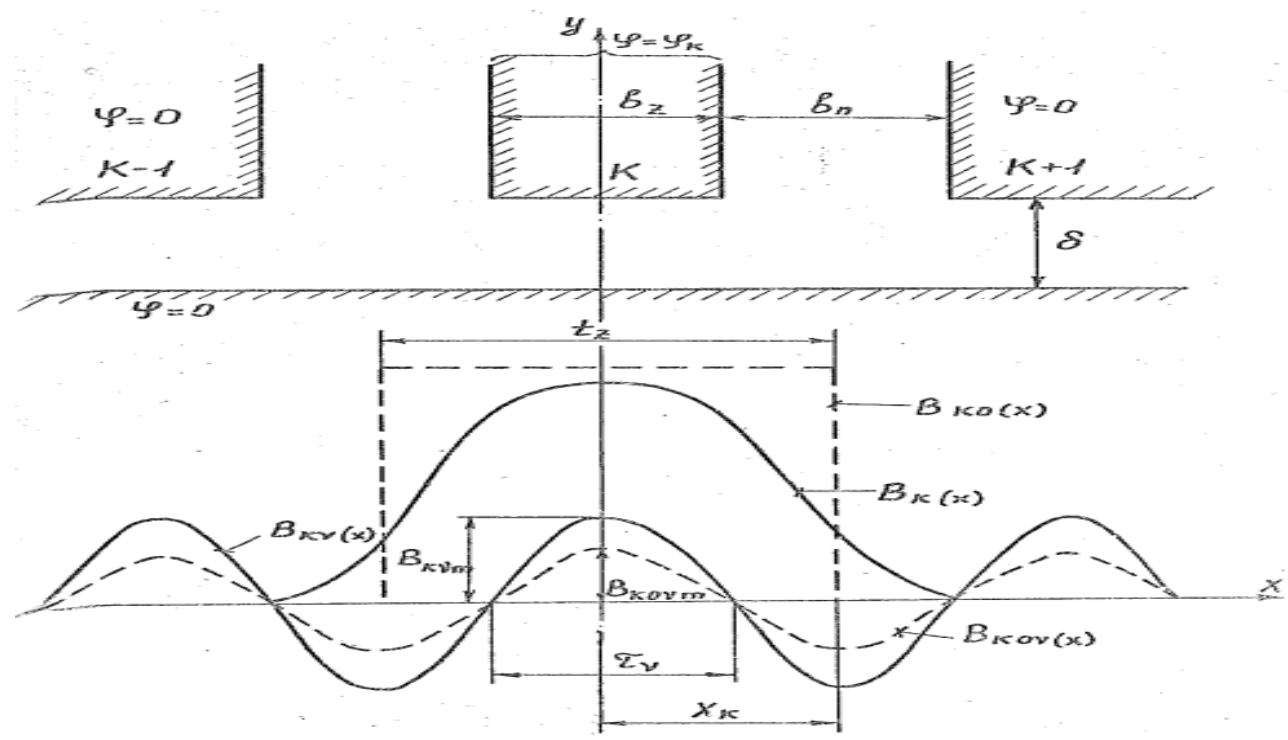

Figure 1. Decomposition the curve of the permeability under the tooth in a fourier series

We will use the conformal transform of plane $(t)$ on the plane $(z)$, and the stripe $(w)$ in Figure 1 . Conversion function can be obtained by integrating the following formula:

$$
\begin{aligned}
& \frac{d z}{d t}=C \frac{\sqrt{(t-a)(t-c}}{(t-b) \sqrt{t(t-1)}} \\
& \frac{d w}{d t}=D \frac{1}{(t-b) \sqrt{t(t-1)}}
\end{aligned}
$$

Where: $C \& D$ are the conversion scale, $a, b \& c$ are the points coefficients on the imaginary axis of the plane $(\mathrm{t})$, which corresponds to the vertices of the multiple angles of the plane $(Z)$.

To determine the fixed given vertices points of the plane with angles equal to zero at the corresponding point $(t=b)$ :

Suppose that the, $t-b=r e^{j \varphi} r \rightarrow o$ and then by differentiation this equation,

$$
d t=\int r e^{j \varphi} d \varphi
$$

As a result of compensation of the $t$ and dt values in $(1,2)$, If $(\mathrm{t})$ is an infinity small and $\varphi$ changes from 0 to $\pi$, the variable $(t)$ is compensated through the value of $(b)$, this changes is equivalent to changing (z) between $(b z+b n)+j y$ and $b z / 2+j y$. When (r) limited to zero, and $(t)$ limited to $(b),(1,2)$ will be solved in a simplified form, and the angle $(\varphi)$ takes only a value between $\mathrm{dt}$ and $(t-b)$, where the other multiple values except $(t-b)$ at $(\varphi)$ varies from zero to $\pi$, remain constant, $(1,2)$ will be re-written as:

$$
\begin{aligned}
& \lim \int_{-(b z / 2)+j y}^{-(b n+b z / 2)+j y} d z=j C \sqrt{\frac{(b-a)(b-c)}{b(b-1)}} \int_{\pi}^{0} d \varphi \\
& \lim \int_{u+j 0}^{u+j \gamma} d \omega=j D \frac{1}{\sqrt{b(b-1)}}
\end{aligned}
$$

After performing the required simplification and differentiation, the scale factors $C$ and $D$ can be expressed as: 


$$
\begin{aligned}
& C=-\frac{b n}{\pi} \sqrt{\frac{b(b-1)}{(b-a)(c-b)}} \\
& D=-\frac{\gamma}{\pi} \sqrt{b(b-1)}
\end{aligned}
$$

If the point $t= \pm \infty$ is corresponding to points that are tangential to the infinity of two parallel surfaces (the air gap) and the angle between them is equal to zero, then (2) can be used to find the relationship between the air gap and the scale factor $C$ [17]. So by compensating $t=R e^{j \varphi}$ where $R= \pm \infty$ ( $\mathrm{R}$-infinity high of the circular radius), the following equation was obtained:

$$
\lim \int_{x+j 0}^{x+j \delta} d z=j C \int_{\pi}^{0} d \varphi
$$

From this equation, the scale factor was obtained as:

$$
C=-\frac{\delta}{\pi}
$$

To find the relationship between the constants $\delta$ and $b z$, vertices corresponding to points at $t=1$ and $\mathrm{t}=\mathrm{a}$ were considered:

$$
\begin{aligned}
& \int_{0+j 0}^{0+j \delta} d z=-j C \int_{0}^{1} \frac{\sqrt{(a-t)(c-t)}}{(b-t) \sqrt{t(1-t)}} d t \\
& \int_{0+j \delta}^{b z / 2+j \delta} d z=C \int_{1}^{a} \frac{\sqrt{(a-t)(c-t)}}{(b-t) \sqrt{t(1-t)}} d t
\end{aligned}
$$

From $(10,11), \delta$ and $b z$ were:

$$
\begin{aligned}
& \delta=-C \int_{0}^{1} \frac{\sqrt{(a-t)(c-t)}}{(b-t) \sqrt{t(1-t)}} d t \\
& b z=-2 C \int_{1}^{a} \frac{\sqrt{(a-t)(c-t)}}{(b-t) \sqrt{t(1-t)}} d t
\end{aligned}
$$

In $(7,10)$ afforded an expression of $\frac{b n}{\delta}$ as shown in $(14)$ :

$$
\frac{b n}{\delta}=\sqrt{\frac{(b-a)(c-b)}{b(b-1)}}
$$

In $(10,13,14), \frac{b z}{\delta}$ was obtained from the following equation:

$$
\begin{aligned}
& \frac{b z}{\delta}=\frac{2}{\pi} \int_{1}^{a} \frac{\sqrt{(a-t)(c-t)}}{(b-t) \sqrt{t(t-1)}} d t \\
& \pi=\int_{0}^{1} \frac{\sqrt{(a-t)(c-t)}}{(b-t) \sqrt{t(1-t)}} d t
\end{aligned}
$$

Substitution of t values $t=C h^{2} \mathrm{~T}$ and $t=\cos ^{2} T$ allowed us to simplify $(16,17)$. Substitution of these $t$ and $\mathrm{dt}$ values into $(16,17)$ gave by:

$$
\begin{aligned}
& \frac{b z}{\delta}=\frac{4}{\pi} \int_{0}^{a r c h \sqrt{a}} \frac{\sqrt{\left(a-C h^{2} \mathrm{~T}\right)\left(c-C h^{2} \mathrm{~T}\right)}}{\left(b-C h^{2} \mathrm{~T}\right)} d t \\
& \pi=2 \int_{0}^{\pi / 2} \frac{\sqrt{\left(a-\cos ^{2} T\right)\left(c-\cos ^{2} T\right)}}{\left(b-\cos ^{2} T\right)} d t
\end{aligned}
$$

\subsection{Calculation of teeth coefficients}

Consider the case when one-side of the gap inside of the stator has teeth with open slots while inside the rotor is a smooth surface without open slots. The harmonics of the MFD are usually determined on the surface of a smooth magnetic core $[18,19]$. In order to study this problem and calculate harmonic fields for one-side with a number of assumptions (permittings), it is necessary to understand the tooth coefficient $\left(C_{v}\right)[20,21]$. The tooth coefficient for arbitrary $(v-u)$ harmonics of the MFD, which is the ratio 
of the amplitude value of the MFD $\left(B_{v m}\right)$ of a slot and the teeth in the surface of the core in one-side of the gap to the amplitude value of the MFD $\left(B_{0 v m}\right)$ of the same harmonics for a smooth surface in the other side of the gap $[22,23]$.

The teeth coefficient $\left(C_{v}=\frac{B_{v m}}{B_{0 v m}}\right)$ depends on the relative values of the width of the slot (bn), the width of the tooth $(b z)$ and the pole pitch $(v-u)$ of the harmonics $(\tau v)$ to the air gap $(\delta)$ the teeth coefficient is located in the interval -4 to +4 for the open slots $[24,25]$. In the case when the pole pitch $(v-u)$ of the harmonics is much larger than the tooth pitch $\tau \gg \tau_{z}=(b n+B z)$ the teeth coefficient is close to the inverse of the air gap coefficient $C_{v}=1 / k \delta$

\section{RESULTS AND DISCUSSION}

Coefficients $(\mathrm{a}, \mathrm{b}, \mathrm{c})$ can be found by solving $(14,17,18)$ with each other using the Newton-Raphson method Figure 2. The integration was calculated using trapezoidal rule method.
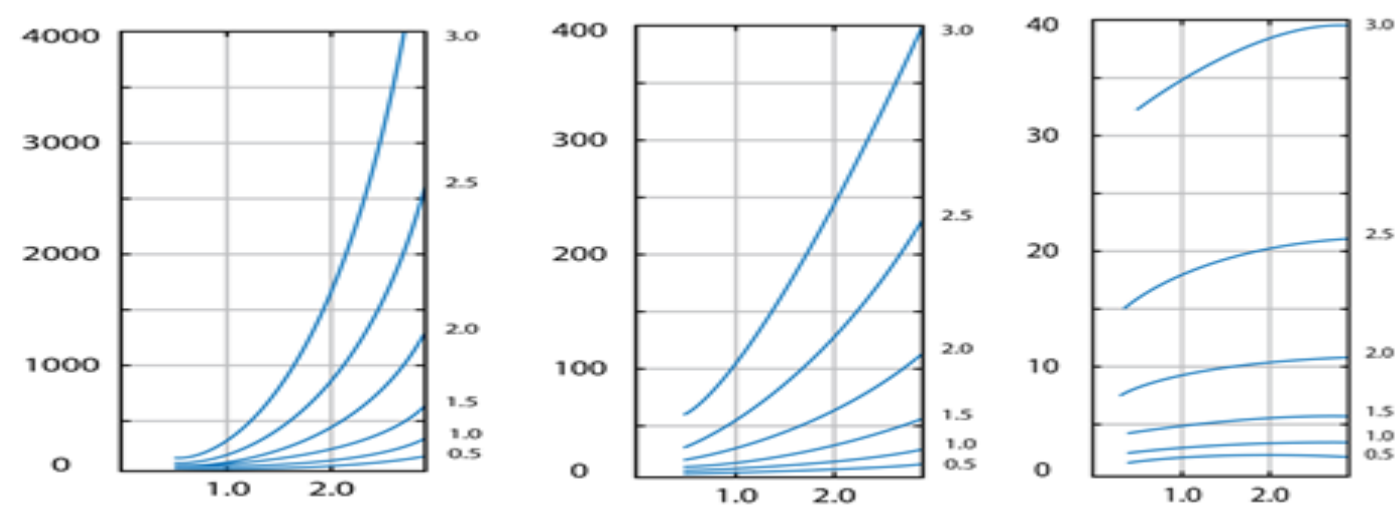

Figure 2. The calculation results of the coefficients a, b, c at different values of $b_{n} / \delta$ and $b_{z} / \delta$

To find the values of the magnetic flux density on $z$ surface, $C$ and $D$ values were introduced to $(1,2)$, accordingly, the following expressions were obtained:

$$
\begin{aligned}
& \frac{d z}{d t}=\frac{\delta}{\pi} \frac{\sqrt{(a-t)(c-t)}}{(b-t) \sqrt{-t(1-t)}} \\
& \frac{d w}{d t}=\frac{\gamma}{\pi} \frac{\sqrt{b(b-1)}}{(b-t) \sqrt{-t(1-t)}}
\end{aligned}
$$

The magnetic flux density on the stripe of $w$ are constant and equal to:

$$
B w=0+j \frac{\mu F_{K}}{\gamma}
$$

In the intervals $\mathrm{b}<\mathrm{t}<\infty$ and $-\infty<\mathrm{t}<0$, from $(19,20)$ and with using $=B w \frac{d_{w}}{d_{z}}$, we find that:

$$
B_{z}=B_{x}+j B_{y}=j B_{0} \sqrt{\frac{b(b-1)}{(a-t)(c-t)}}
$$

where, $\quad B_{0}=\mu_{0} \frac{F_{K}}{\delta}$

On the surface of a smooth core with $y=0$

$$
B_{y(x)}=B_{0} \sqrt{\frac{b(b-1)}{(a-t)(c-t)}}
$$

For $t=0$ along the axis of the tooth, the maximum magnetic flux density on the surface of a smooth core equals: 


$$
B_{\max }=B_{0} \sqrt{\frac{b(b-1)}{a c}}
$$

In (19) was used for determining the values of the magnetic flux density in points $Z=-x_{0}+j \delta$ corresponding to $t=t_{0}$

$$
\int_{0+J 0}^{-x_{0}+j \delta} d_{z}=\frac{\delta}{\pi} \int_{0}^{-t_{0}} \frac{\sqrt{(a-t)(c-t)}}{(b-t) \sqrt{t(1-t)}} d t
$$

By compensating the value $t=-S h^{2} T$ in (26), the following equation was obtained:

$$
\frac{X_{0}}{\delta}=\frac{2}{\pi} \int_{0}^{a r c S h^{2} \sqrt{t}} \frac{\sqrt{\left(a+S h^{2} T\right)\left(c+S h^{2} T\right)}}{b+S h^{2} T} d t
$$

The values of the magnetic induction of other points on a smooth surface of the shape can be found from (24), when determining the value of $t$ from the solution of (27) by the Newton-Raphson method.

Curves $\mathrm{B}(\mathrm{x})$ for different core teeth can be easily calculated at the front stage and entered into the program for further calculations with the adjusted structure of the tooth layer. Curves $\mathrm{B}(\mathrm{x})$ are simply repeated on each tooth contour forming on a smooth core surface shown in Figure 3. The aggregate of the harmonics (MFD) is the amplitude value $(v-u)$. The harmonic value is defined as:

$$
B_{K v m}=\frac{4 F_{K \mu_{0}}}{Z \delta t_{z}} \int_{0}^{\alpha / 2} B_{(X)} \cos \left(\frac{2 \pi v}{Z t_{z}}\right) X d X
$$

Where $(\alpha)$ is the zone of existence of the magnetic field of the tooth contour. In view of the symmetry of the curve $B(x)$, its diffusion in a series contains only even harmonics and also a constant component MFD $B_{\delta}$. The field curve in the gap will be:

$$
B_{K(X)}=B_{\delta}+\sum_{v=1}^{\infty} B_{K v m} \cos \frac{2 K v}{Z t_{Z}} X
$$

In the absence of a tooth, the amplitude value of an arbitrary $(v-u)$ harmonic field from (MFD) $F k$ of the tooth contour will be:

$$
B_{K 0 v m}=\frac{2 \mu_{0}}{\pi v} \frac{F K}{\delta} \sin \frac{2 \pi v}{Z}
$$

The coefficient that takes into account the effect of teething on $v$-harmonic on the surface of a smooth core is equal to:

$$
C_{v}=\frac{B_{K v m}}{B_{K 0 v m}}=\frac{2 \pi v}{Z t_{Z}}\left(\sin \frac{2 \pi v}{Z}\right)^{-1} \int_{0}^{a / 2} B_{(X)} \cos \left(\frac{2 \pi v}{Z t_{Z}}\right) X d X
$$

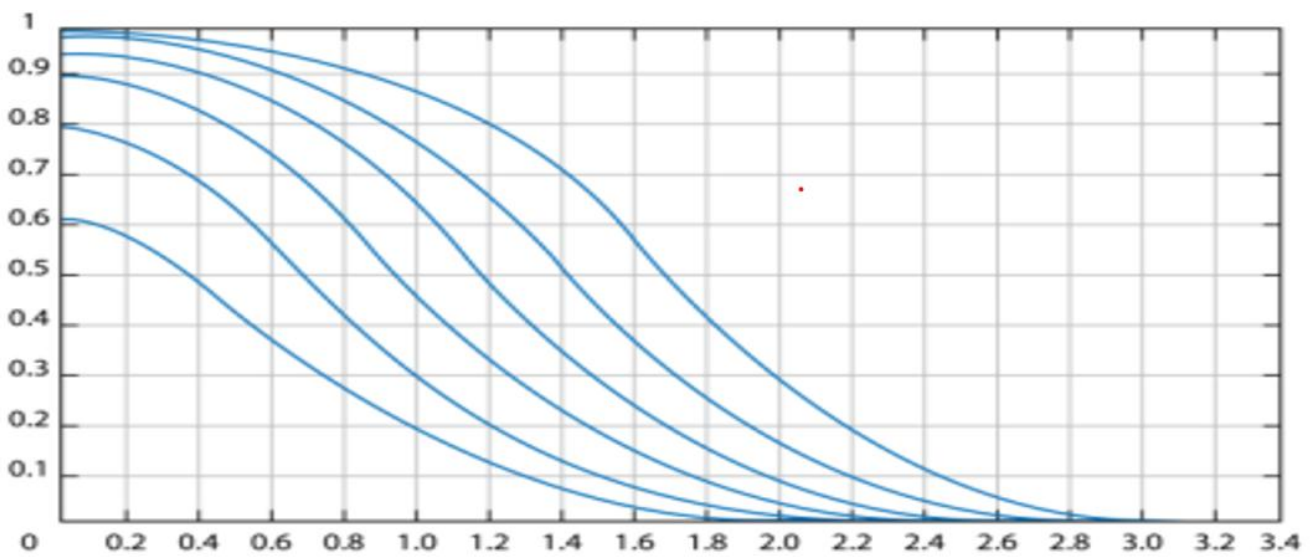

(a)

Figure 3. Permeability curves at, (a) $\mathrm{Z}=30$ and $\mathrm{P}=1$, (b) $\mathrm{Z}=42$ and $\mathrm{P}=1$, (c) $\mathrm{Z}=54$ and $\mathrm{P}=1$, (d) $\mathrm{Z}=60$ and $\mathrm{P}=1$ 


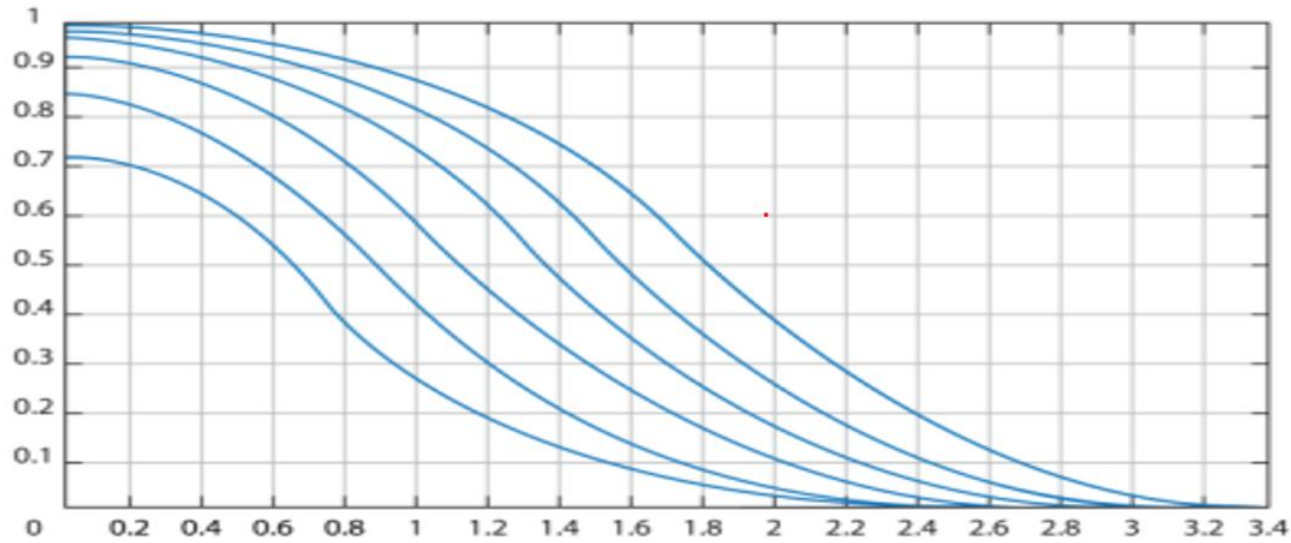

(b)

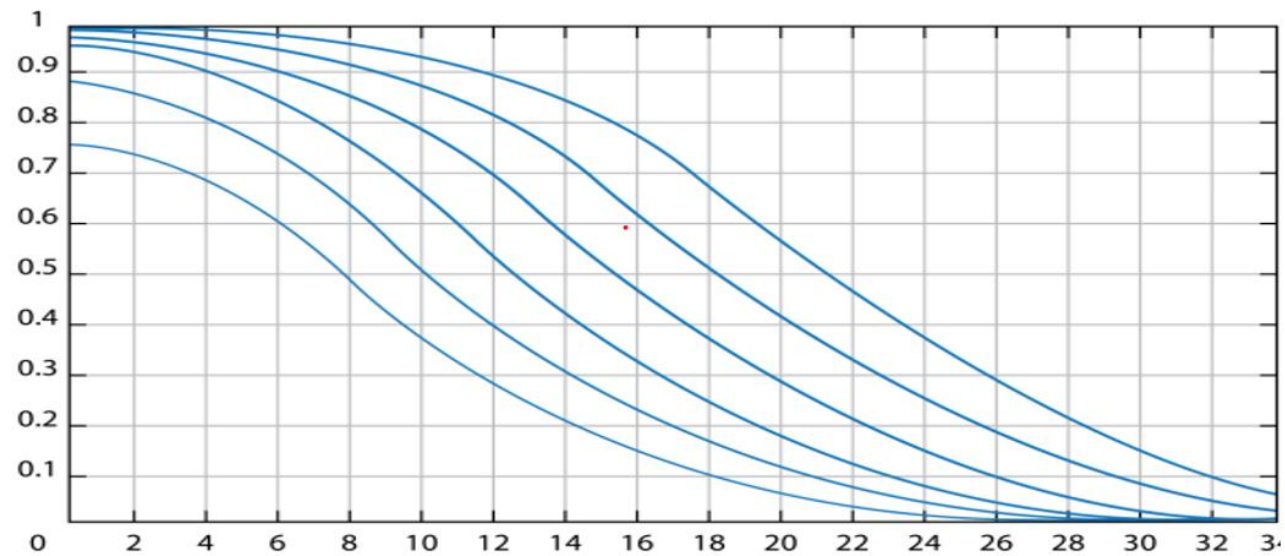

(c)

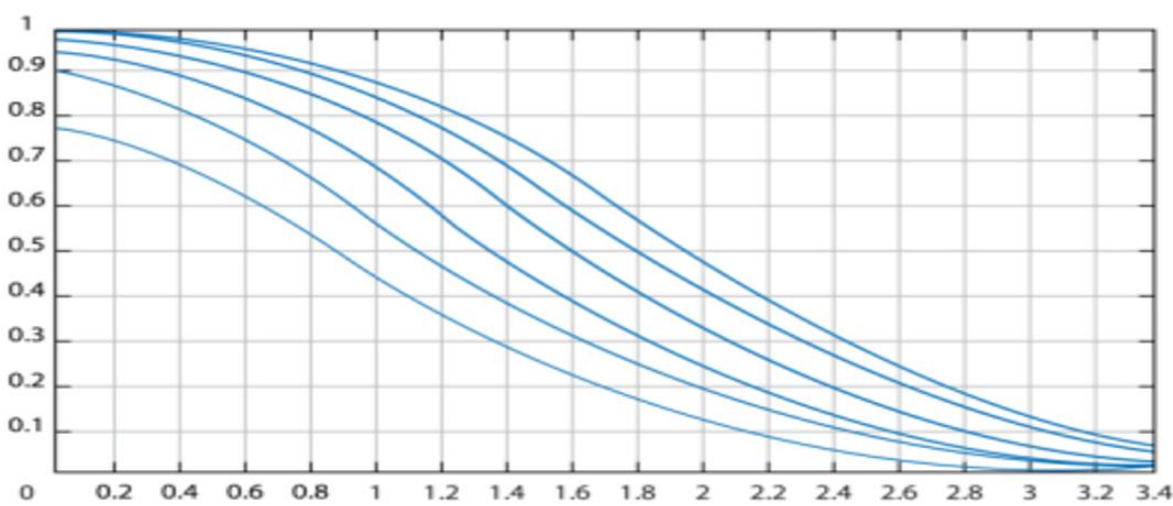

(d)

Figure 3. Permeability curves at, (b) $\mathrm{Z}=42$ and $\mathrm{P}=1$, (c) $\mathrm{Z}=54$ and $\mathrm{P}=1$, (d) $\mathrm{Z}=60$ and $\mathrm{P}=1$ (continue)

\section{CONCLUSION}

In this paper the general mathematical model for the calculation and analysis of asynchronous systems and transient cases in an asynchronous synchronous large electrical machines was developed, the theory of magnetic fields in the teeth's circuits with a smooth surface of the rotor was used and at the same time, high harmonics of magnetic fields and its effect on the transient cases is calculated and investigated. Performance curves were investigated using Matlab codes and evaluated under different 
values of $C_{v}$ factor. The results confirm the possibility of improving and reducing the tooth and noise harmonics on the sinusoidal wave form, which is reflected on the machines starting. Also the tooth harmonic reduction can decrease the unbalanced magnetic force in the windings MMF.

\section{REFERENCES}

[1] P. Zheng, F. Wu, Y. Lei, Y. Sui, B. Yu, "Investigation of a Novel 24-Slot/14-Pole Six-Phase Fault-Tolerant Modular Permanent-Magnet In-Wheel Motor for Electric Vehicles," Energies, vol. 6, no. 10, pp. 4980-5002, 2013.

[2] Nor Shahida Hasan, et al., "Harmonic Suppression of Shunt Hybrid Filter Using LQR-PSO based," International Journal of Electrical and Computer Engineering, vol. 7, no. 2, pp. 869-876, 2017.

[3] Yu. Kruchinina and L. Yu. Shtainle, “Air gap magnetic field spectrum calculation method," St. Petersburg State Polytechnical University Journal, no. 117, pp. 221-226, 2011.

[4] I. Yu. Kruchinina, L. Yu Shtainle, "Magneto-motive Force of Stator Multiphase Windings with Fractional Number of Slots Q per Pole and Phase," Russian Electrical Engineering, vol. 81, no. 8, pp. 410-414, 2010.

[5] G. Dajaku and D. Gerling, "Analysis of different PM machines with concentrated windings and flux barriers in stator core," 2014 International Conference on Electrical Machines (ICEM), Berlin, pp. 375-384, 2014.

[6] Z. Azar and Z. Q. Zhu, "Investigation of electromagnetic performance of salient-pole synchronous reluctance machines having different concentrated winding connections," International Electric Machines \& Drives Conference, Chicago, IL, pp. 359-366, 2013.

[7] Bineeta Mukhopadhyay, Rajib Kumar Mandal, Girish Kumar Choudhary, "Voltage Compensation in Wind Power System Using STATCOM Controlled by Soft Computing Techniques," International Journal of Electrical and Computer Engineering, vol. 7, no. 2, pp. 667-680, April 2017.

[8] M. V. Cistelecan, F. J. T. E. Ferreira and M. Popescu, "Three phase tooth-concentrated interspersed windings with low space harmonic content," The XIX International Conference on Electrical Machines-ICEM 2010, Rome, pp. $1-6,2010$

[9] G. Dajaku and D. Gerling, "A novel tooth concentrated winding with low space harmonic contents," 2013 International Electric Machines \& Drives Conference, Chicago, IL, pp. 755-760, 2013.

[10] A. O. Di Tommaso, F. Genduso and R. Miceli, "A software for the evaluation of winding factor harmonic distribution in high efficiency electrical motors and generators," 2013 Eighth International Conference and Exhibition on Ecological Vehicles and Renewable Energies (EVER), Monte Carlo, pp. 1-6, 2013.

[11] E. Fornasiero, N. Bianchi and S. Bolognani, "Slot Harmonic Impact on Rotor Losses in Fractional-Slot PermanentMagnet Machines," in IEEE Transactions on Industrial Electronics, vol. 59, no. 6, pp. 2557-2564, June 2012.

[12] O. Moros, D. Gerling, "New 30-Teeth/14-Poles Concentrated Winding for Use in Induction Machines," 4. Tagung Elektrische Antriebstechnologie für Hybrid- und Elektrofahrzeuge, Haus der Technik, Muenchen, Germany, vol. 131, pp. 352-361, 2013.

[13] M. V. Cistelecan, F. J. T. E. Ferreira and M. Popescu, "Three phase tooth-concentrated multiple-layer fractional windings with low space harmonic content," 2010 IEEE Energy Conversion Congress and Exposition, Atlanta, GA, pp. 1399-1405, 2010.

[14] G. Dajaku and D. Gerling, "A Novel 24-Slots/10-Poles Winding Topology for Electric Machines," 2011 IEEE International Electric Machines \& Drives Conference (IEMDC), Niagara Falls, ON, pp. 65-70, 2011.

[15] G. Dajaku and D. Gerling, "A novel 12-teeth/10-poles PM machine with flux barriers in stator yoke," 2012 XXth International Conference on Electrical Machines, Marseille, pp. 36-40, 2012.

[16] O. Kayabasi,F. Erzincanli, "Shape optimization of tooth profile of a flexspline for a harmonic drive by finite element modelling," Materials and Design, vol. 28, no. 2, pp. 441-447, 2007.

[17] M. Luqman, M. Jamil, Z. Z. Zolkapli, A. Jidin, R. Nor, F. R. Othman, T. Sutikno, "Electromagnetic Performance due to Tooth-tip Design in Fractional-slot PM Brushless Machines," International Journal of Power Electronics and Drive Systems, vol. 6, no. 4, pp. 860-868, 2015.

[18] A. Y. Al-Rawashdeh, "Simulation and analysis of the possibilities of traction electric motor," Indonesian Journal of Electrical Engineering and Computer Science, vol. 14, no. 1, pp. 51-58, 2019.

[19] S. Malathi, J. Jayachandran, "Neural Network based p-q-r Theory for Harmonic Reduction and Neutral Current Mitigation," International Journal of Electrical and Computer Engineering (IJECE), vol. 8, no. 2, pp. 825-836, April 2018.

[20] M. Tamilvani, K. Nithya, M. Srinivasan, S.U. Prabha, "Harmonic Reduction in Variable Frequency Drives Using Active Power Filter," Bulletin of Electrical Engineering and Informatics, vol. 3, no. 2, pp. 119-126, 2014.

[21] G. Dajaku, W. Xie and D. Gerling, "Reduction of Low Space Harmonics for the Fractional Slot Concentrated Windings Using a Novel Stator Design," in IEEE Transactions on Magnetics, vol. 50, no. 5, pp. 1-12, May 2014

[22] X. Chen and J. Wang, "Magnetomotive force harmonic reduction techniques for fractional-slot non-overlapping winding configurations in permanent-magnet synchronous machines," in Chinese Journal of Electrical Engineering, vol. 3, no. 2, pp. 102-113, September 2017.

[23] M. Wu, W. Zhao, J. Ji, J. Zheng, J. Luo, "Reduction of Tooth Harmonic in Fractional-Slot Concentrated-Winding Permanent-Magnet Machines Using New Stator Design," Journal of Magnetics, vol. 23, no. 2, pp. 218-228, 2018.

[24] T. Tjahjowidodo, F. Al-Bender, H. Van Brussel, "Theoretical modelling and experimental identification of nonlinear torsional behaviour in harmonic drives," Mechatronics, vol. 23, no. 5, pp. 497-504, August 2013. 
[25] Z. Chen, D. Zou, M. Xu, Z. Li and H. An, "Harmonic Analysis of Magnetic Field in Fractional-Slot IPMSM with Segment Permanent Magnets," 2018 21st International Conference on Electrical Machines and Systems (ICEMS), Jeju, pp. 70-74, 2018.

\section{BIOGRAPHIES OF AUTHORS}
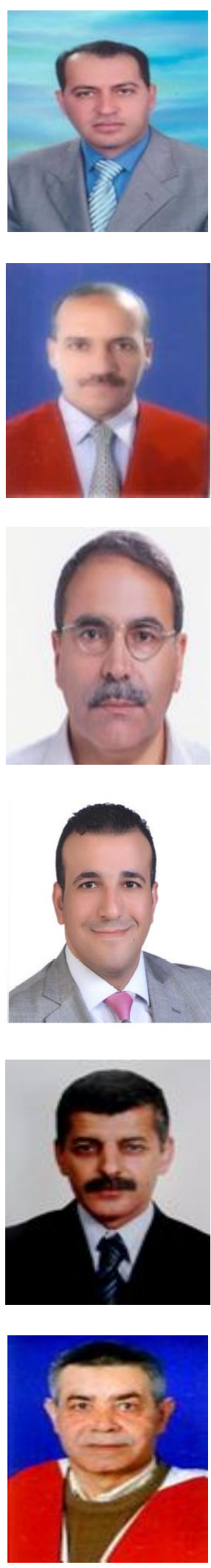

Dr. Ayman Y. Al-Rawashdeh. PhD. Mechatronics Engineering was born on 01 January 1970 in Jordan. He obtained his Diploma degree in 1995 and $\mathrm{PhD}$ degree in 2008 in the field of Mechatronics Engineering. Currently, Dr. Al-Rawashdeh is an Associate Professor at the Department of Electrical Engineering, Faculty of Engineering Technology, Al-Balqa Applied University, Jordan. His main research interests include renewable energy, drive system analysis and simulations

Dr. Ali Dalabeeh received his Bachelor degree in Electrical Power Engineering from Alleppo University/Engineering College, Syria in 1981 and $\mathrm{Ph}$. D in Electrical Engineering from Moscow Power Institute in 1988. Currently he is an Associate Professor in Department of Electrical Engineering, Faculty of Engineering Technology, Al-Balqa Applied UniversityJordan. His research interests include renewable energy, energy efficiency, and deregulation in electrical power systems.

Dr. Abdallah R. Alzyoud is an Associate Professor of Electrical Power Engineering, Faculty of Engineering Technology, Al-Balqa Applied University-Jordan. He recived his Ph.D in Electrical Power Engineering from Kiev Polytechnic Institute, 1992. His research intresets include renewable energy, voltage and reactive power control and power system protection.

Dr. Ashraf Samarah was born in Irbid, Jordan, on September 29, 1980. He received B.Sc. degree in 2003, M.Sc. degree in Communications and Electronicengineering with honors from Jordan University of Science and Technology (JUST) in 2003, and a Ph.D. degree in Electrical Energy Engineering, fromthe University of Siegen, Siegen, Germany, in 2012, respectively. He has worked in the area of photovoltaic energy systems and electrical signals during the last ten years.

Dr. Ghazi Qaryouti PhD. Mechatronics. Eng, was born on $24^{\text {th }}$ June 1958 in Jordan. He obtained bachelor degree in 1982 and $\mathrm{PhD}$ degree in 2015 in the field of Mechatronics Engineering. Currently he works as an Assistant Professor at the Mechatronics Department Faculty Engineering Technology in Al-Balqa Applied University, Jordan. His main interest is renewable energy, power electronics, image proccessing and drive system analysis.

Dr. Omar Albarbarawi PhD. Electrical Engineering, was born on $25^{\text {th }}$ march 1952 in Jordan. He obtained Diploma degree in 1980 and $\mathrm{PhD}$ degree in 1986 in field of Electrical Engineering. Currently he works as an Assistant Professor at the Department of Electrical Engineering, Faculty Engineering Technology, Al-Balqa Applied University, Jordan. His main research interests include power system protection and renewable energy. 